\title{
An interesting case of neurofibroma of face
}

\section{Arjun Cukkemane, Vickey Katheria, Sreekar Harinatha}

\author{
Department of Dermatology, M.V.J. Medical College \& Research Hospital, Hoskote, Bangalore, India
}

Corresponding author: Dr. Arjun Cukkemane, e-mail: arjuncm226@gmail.com

Sir,

Neurofibromatosis or Von Recklinghausens disease is rare and found only in 1-4000 births.It is Autosomal Dominant, Involving chromosome 17. It is associated with pigmented spots (coffee coloured) in the skin, commonly seen on the back, abdomen and limbs (café au lait spots) [1].

A 45 years old female, presented with complains of Painless large swelling over right side of nose and upper lip (Fig. 1) since childhood. The swelling was present since childhood, was initially the size of a peanutand gradually progressed to the present size of a lemon. There was a gradual increase in size of the swelling. There was no pain associated with the swelling. She also complained of similar swellings all over the body (Fig. 2) and right nasal obstruction. patients father and brother have similar swellings all over the body. On examination a Single, large diffuse irregular swelling measuring $6 \times 5 \mathrm{cms}$ over the right alae of the nose extending to the upper lip and nasolabial fold, soft in consistency, non tender.

Multiple, nodular swellings seen all over the body (Fig. 3).

On ophthalmic examination, Lisch nodules were present over iris. No evidence of optic glioma on fundoscopy.

ENT Examination- Normal. A provisional diagnosis of Neurofibromatosis Type 1/Von Recklinghausens disease was made systemic examination was normal and all routine investigations were normal. Debulking was planned Incision was made along the edge of the swelling along the alae of the nose and the lip.Incision was deepened till Orbicularis Oris. Then entire swelling was elevated off the muscle.

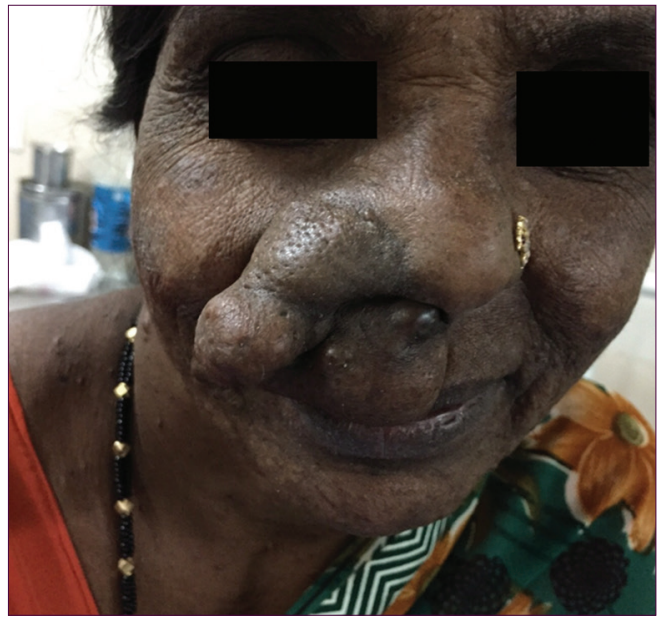

Figure 1: Pre operation pic of lesion over nose.

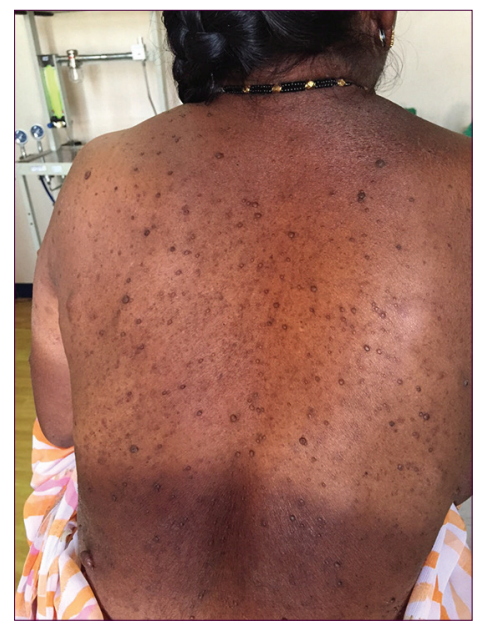

Figure 2: Multiple macules and lesions over back typical of neurofibromatosis.

Another plane was created at sub-dermal level and skin was separated. The swelling was de-bulked and extra skin excised. Skin was re-draped, adjusted and sutured with ethilon 6-0 swelling was sent for histopathology (Fig 4). According to the report, Multiple sections studied show epidermis, dermis and

\footnotetext{
How to cite this article: Cukkemane A, Katheria V, Harinatha S. An interesting case of neurofibroma of face. Our Dermatol Online. $2016 ; 7(4): 479-481$.

Submission: 04.02.2016; Acceptance: 27.07.2016

DOI: 10.7241/ourd.20164.131
} 


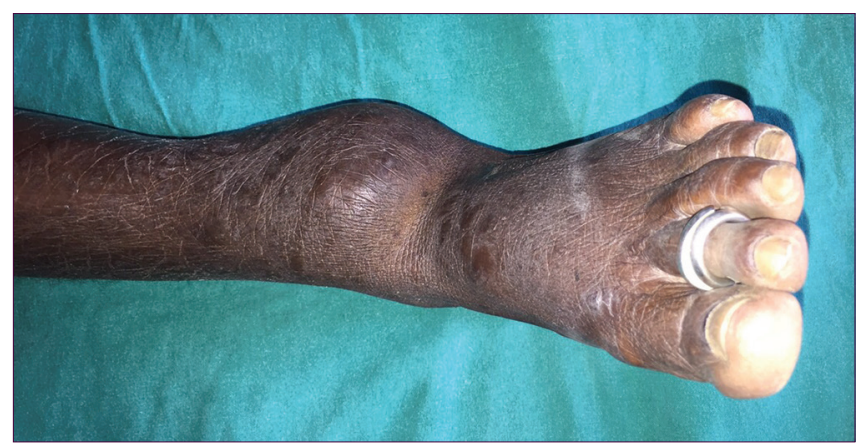

Figure 3: Swelling over left limb wid deformity.

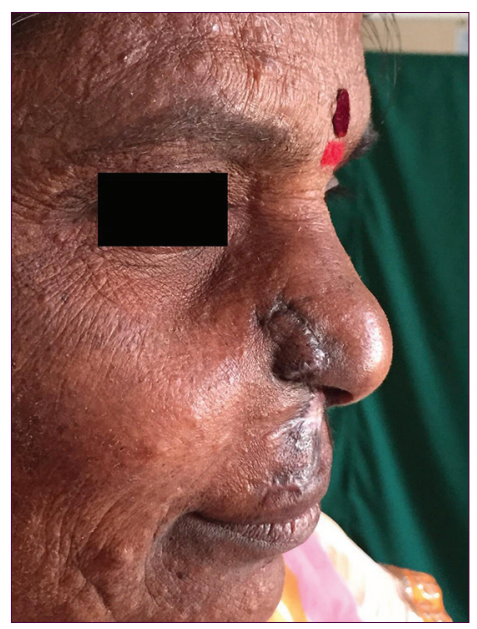

Figure 4: Post operation pic after excision and plastic reconstruction.

an ill circumscribed tumour. Epidermis shows mild hyperkeratosis, acanthosis and pigment incontinence in the upper dermis. Lower dermis shows an ill circumscribed tumour composed of bundles and nodules of spindle cells having spindle shaped to wavy nucleus amidst which are seen one prominent blood vessels with inflammatory cell infiltrate. Borders show infiltration into the adjacent fibro adipose tissue and muscle bundles (Fig 5).

Impression-Excised swelling shows diffuse neurofibroma.

Neurofibromatosis or von Recklinghausens disease is rare and found in 1-4000 births. It is autosomal dominant, involving chromosome 17. It is associated with pigmented spots (coffee coloured) in the skin, commonly seen on the back, abdomen and limbs (café au lait spots). Axillary freckling and lisch nodules may be present $[1,2]$.

Diagnostic criteria include two or more of the following $[2,3]$ :

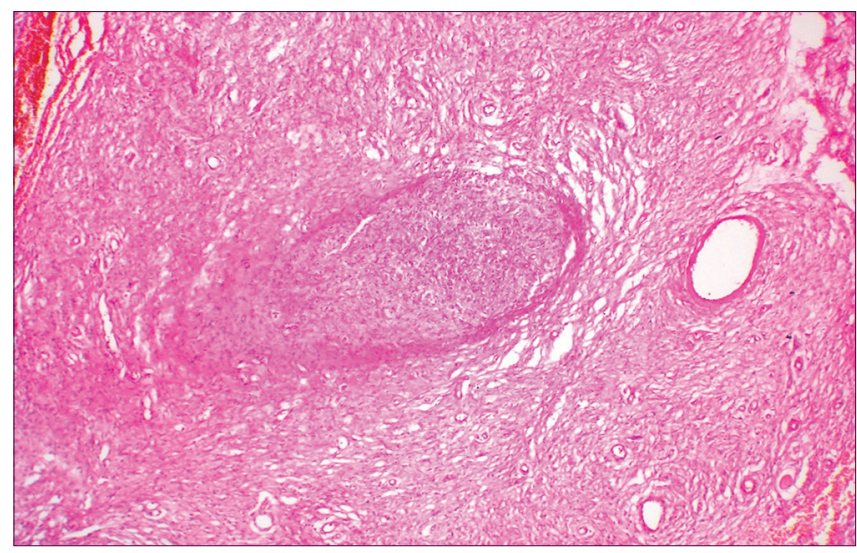

Figure 5: Microscopic appearance of excised specimen.

Six or more café-au-lait spots $1.5 \mathrm{~cm}$ or larger in postpubertal individuals, $0.5 \mathrm{~cm}$ or larger in pre-pubertal individuals.

Two or more neurofibromas of any type or one or more plexiform neurofibroma.

Freckling in the axilla or groin.

Optic glioma (tumor of the optic pathway).

Two or more Lisch nodules (benign iris hamartomas).

A distinctive bony lesion: Dysplasia of the sphenoid bone or dysplasia or thinning of long bone cortex.

A first-degree relative with NFl.

It may be associated with MEN type 2 (multiple neurofibromatosis of eyelid, lips and face, medullary carcinoma of thyroid, pheochromocytoma and hyperparathyroidism.

Complications include -sarcomatous changes (5\%), cystic degeneration, haemorrhage into the tissues, muscle atrophy $[4,5]$.

Treatment - Excision/Debulking.

The patient described here is a very typical case of NF-1 which presents a considerable interest because of the high generalization of the skin lesion. In such cases, a detailed patient investigation is required,because of the possibility for generalized involvement of other organs. The proper clinical and genealogic analysis is important for the determination of genetic risk and prognosis for relatives of proband. The treatment of such kind of patient is surgical, 
www.odermatol.com

seeking to achieve cosmetic improvement and may be only palliative.

\section{REFERENCES}

1. El Bouihi M, Lahmiti S, Aimadeddine S, Zaroual A, Fawzi S, Hattab NM. A columellar deformity caused by a congenital schwannoma. Our Dermatol Online. 2013;4:224-5.

2. Chang P, Meaux T, Calderon G. Solitary Neurofibroma. Our Dermatol Online. 2015;6:362-4.

3. Hassan I, Keen A, Shah PA. Facial Plexiform neurofibromatosis in a patient with neurofibromatosis type 1: a case report. Our Dermatol
Online. 2012;3:24-7.

4. Lubinska M, Sworczak K. Pheochromocytoma and paraganglioma: an overview. OncoReview. 2014;4:A18-A25.

5. Walker JA, Bernards A. A Drosophila screen identifies neurofibromatosis-1 genetic modifiers involved in systemic and synaptic growth. Rare Dis. 2014;2:e28341.

Copyright by Sreekar Harinatha, et al. This is an open access article distributed under the terms of the Creative Commons Attribution License, which permits unrestricted use, distribution, and reproduction in any medium, provided the original author and source are credited.

Source of Support: Nil, Conflict of Interest: None declared. 